\begin{tabular}{|c|c|c|c|}
\hline \multirow{2}{*}{$\begin{array}{r}\text { Case Reports in } \\
\text { Gastroenterology }\end{array}$} & \multicolumn{2}{|c|}{ Case Rep Gastroenterol 2015;9:272-277 } & \multirow[b]{2}{*}{$\begin{array}{l}\text { Karger } \\
\text { Open'access }\end{array}$} \\
\hline & $\begin{array}{l}\text { DOI: 10.1159/000438784 } \\
\text { Publisnea Oninne. July 3I, } 2015\end{array}$ & $\begin{array}{l}\text { (C) } 2015 \text { S. Karger AG, Basel } \\
1662-0631 / 15 / 0092-0272 \$ 39.50 / 0 \\
\text { www.karger.com/crg }\end{array}$ & \\
\hline & \multicolumn{2}{|c|}{$\begin{array}{l}\text { This is an Open Access article licensed under the terms of the Creative Commons } \\
\text { Attribution-NonCommercial } 3.0 \text { Unported license (CC BY-NC) (www.karger.com/OA } \\
\text { license), applicable to the online version of the article only. Distribution permitted for non } \\
\text { commercial purposes only. }\end{array}$} & \\
\hline
\end{tabular}

\title{
Two Cases of Severe Ulcerative Colitis with Colonic Dilatation Resolved with Tacrolimus Therapy
}

\author{
Ryohei Hayashi $^{\mathrm{a}}$ Yoshitaka Ueno $^{\mathrm{a}}$ Shinji Tanaka ${ }^{\mathrm{a}}$ Shintaro Sagami ${ }^{\mathrm{b}}$ \\ Kenta Nagai ${ }^{b}$ Norifumi Shigemoto ${ }^{c}$ Shinnosuke Uegami ${ }^{c}$ \\ Wataru Shimizu $^{c}$ Yusuke Watadani $^{c}$ Hiroki Ohge $^{c}$ Kazuaki Chayama $^{b}$ \\ Departments of ${ }^{\mathrm{a}}$ Endoscopy, ${ }^{\mathrm{b}}$ Gastroenterology and Metabolism and ${ }^{\mathrm{c}}$ Surgery, Hiroshima \\ University Hospital, Hiroshima, Japan
}

\section{Key Words}

Ulcerative colitis · Tacrolimus · Toxic megacolon $\cdot$ Intestinal tract dilatation

\begin{abstract}
We report 2 cases of ulcerative colitis (UC) with intestinal tract dilatation treated with tacrolimus. They were 53- and 64-year-old males, who had been admitted to local hospitals for increasing severity of their UC symptoms. Treatment for severe UC was immediately started, but both cases were refractory to corticosteroid therapy; they were then transferred to our hospital. When they were referred to our hospital, they had frequent bloody diarrhea, fever, severe abdominal pain, and even dilatation of the transverse colon on abdominal X-ray test. They were treated with oral tacrolimus medication, and their symptoms improved immediately. Dilatation of the transverse colon was improved on plain X-ray at 2 weeks after starting therapy, and emergency colectomy could be avoided. These 2 cases may suggest that tacrolimus is effective for UC with colonic dilatation as a rescue therapy. $02015 \mathrm{~S}$. Karger AG, Basel
\end{abstract}

\section{Introduction}

Ulcerative colitis (UC) is a chronic inflammatory disorder of the colon characterized by colonic mucosal ulceration [1]. In Japan, we have several therapies which induce remission in severe UC, including corticosteroids, anti-TNF- $\alpha$ therapy (infliximab, adalimumab), leukocytapheresis, and tacrolimus. Tacrolimus is an immunosuppressive macrolide isolated from Streptomyces tsukubaensis, and it is known for potent inhibition activity of helper T lympho-

KARGER 125/s $\quad \begin{aligned} & \text { Yoshitaka Ueno, MD, PhD } \\ & \text { Department of Endoscopy, Hiroshima University Hospital } \\ & 1-2-3 \text { Kasumi, Minami-ku } \\ & \text { Hiroshima 734-8551 (Japan) } \\ & \text { E-Mail yueno@hiroshima-u.ac.jp }\end{aligned}$


Hayashi et al.: Two Cases of Severe Ulcerative Colitis with Colonic Dilatation Resolved with Tacrolimus Therapy

cyte activation [2]. It has been shown to be an effective treatment for inducing remission in patients with severe UC that is refractory to high-dose corticosteroids [2, 3]. On the other hand, when a patient with UC has the complication of colonic dilatation, we must be concerned about a shift to toxic megacolon. Toxic megacolon is a fatal complication of UC characterized by total or segmental nonobstructive colonic dilatation of at least $6 \mathrm{~cm}$. Toxic megacolon involves adaptation of the emergency surgery. However, treatment for UC with colonic dilatation of less than $6 \mathrm{~cm}$ has not yet been established, and the efficacy of tacrolimus as a rescue therapy for UC with colonic dilatation has not been reported.

We report 2 cases of UC with intestinal tract dilatation treated with tacrolimus in which emergency colectomy was avoided. These 2 cases suggest that tacrolimus is effective for UC with colonic dilatation as a rescue therapy.

\section{Case Report}

Case 1

A 53-year-old man was transferred from a local hospital for steroid-resistant UC. He was diagnosed with UC (proctitis type) at the age of 48 and maintained remission for 5 years. He was admitted to the local hospital complaining of worsening abdominal pain and bloody diarrhea. Colonoscopy showed that inflammation extended to the whole colon, and he was treated with medication consisting of 5-ASA, granulocytapheresis (twice a week), and highdose prednisolone $(1.0 \mathrm{mg} / \mathrm{kg} /$ day), but bloody diarrhea did not improve, and anemia progressed such that blood transfusions were necessary. When he was referred to our hospital, he was having bloody diarrhea 11 times a day and severe abdominal pain. The results of the blood examination were: white blood cells 13,630 $\mu$, hemoglobin $9.6 \mathrm{~g} / \mathrm{dl}$, serum albumin $2.4 \mathrm{~g} / \mathrm{dl}$, and C-reactive protein $5.7 \mathrm{mg} / \mathrm{dl}$. Plain X-ray showed dilatation of the transverse colon reaching diameters of $5.5 \mathrm{~cm}$ (fig. 1a).

After we had obtained full informed consent from the patient, oral tacrolimus medication was started at a dose of $0.05 \mathrm{mg} / \mathrm{kg} / \mathrm{day}$. According to a previous study [2], the dosage of tacrolimus was adjusted to produce a trough blood level of $10-15 \mathrm{ng} / \mathrm{ml}$ during the first 2 weeks, and thereafter, the trough blood level was maintained at a lower level of between 5 and $10 \mathrm{ng} / \mathrm{ml}$.

One week later, bloody diarrhea had disappeared and anemia had improved. The transverse colon dilatation was improved on plain X-ray after 2 weeks of therapy (fig. 1b). Colonoscopy showed improvement in multiple ulcers (fig. 1c), and a barium enema examination detected pseudopolyposis in the transverse and descending colon, without active ulcers or stenosis (fig. 1d). Oral tacrolimus was continued for 3 months, and the patient started azathioprine ( $25 \mathrm{mg} /$ day) 1 month before the cessation of tacrolimus.

Case 2

A 64-year-old man was transferred from a local hospital for steroid-resistant UC. He was diagnosed with UC (left-sided colitis type) at the age of 63 and was treated with 5-ASA, which induced remission. Eight months later, he had a relapse of the disease in association with fever, abdominal pain, and bloody diarrhea. He was admitted to the hospital and treated with leukocytapheresis (two sessions per week, four sessions in total), high-dose prednisolone $(1.0 \mathrm{mg} / \mathrm{kg} /$ day), and steroid pulse therapy (hydrocortisone 1,000 mg/day for 3 days), but his symptoms did not improve. When he was referred to our hospital, he was having bloody diarrhea 10 times a day and abdominal pain, and his temperature was $39.0^{\circ} \mathrm{C}$. The results of the blood examination were: white blood cells $110,500 \mu \mathrm{l}$, hemoglobin 7.0 
Hayashi et al.: Two Cases of Severe Ulcerative Colitis with Colonic Dilatation Resolved with Tacrolimus Therapy

$\mathrm{g} / \mathrm{dl}$, serum albumin $1.0 \mathrm{~g} / \mathrm{dl}$, and C-reactive protein $5.1 \mathrm{mg} / \mathrm{dl}$. Plain X-ray revealed dilatation of the transverse colon reaching diameters of $5.0 \mathrm{~cm}$ (fig. 2a). Because we were concerned about progression to toxic megacolon, we continued medical treatment in cooperation with the surgeons.

Oral tacrolimus was started as described for case 1. Ganciclovir injection was also started at a dose of $1,000 \mathrm{mg} /$ day because his serum was positive for cytomegalovirus antigen. One week after beginning the therapy, bloody diarrhea had disappeared and the serum Creactive protein level had decreased. Dilatation of the transverse colon was improved on plain X-ray at 2 weeks after starting therapy (fig. 2b). Colonoscopy performed 32 days later showed diffuse inflammatory mucosa with edema, erosions, and ulcers in the rectum and sigmoid colon. However, the proximal sigmoid colon became severely constricted, and we were not able to insert the colonoscope deeper into the colon (fig. 2c). Barium enema examination showed extensive stenoses from the proximal sigmoid colon to the ascending colon (fig. 2d). Because we thought that oral intake might be difficult due to these strictures, we decided to perform a subtotal colectomy. The pathological tissue of the resected colon showed that inflammatory cells had profoundly infiltrated the submucosal layer to the muscle layer, and this lesion had become severely fibrotic.

\section{Discussion}

Tacrolimus is an immunomodulator isolated from the fermentation broth of $S$. tsukubaensis in Japan [4]. A randomized, controlled study demonstrated the efficacy and safety of oral tacrolimus for inducing remission of refractory UC [2], and there are many case reports showing tacrolimus to be effective for UC refractory to other treatments [5, 6]. However, there are, to our knowledge, no reports of treatment of UC with intestinal tract dilatation with tacrolimus, and no guidelines for medical treatment of this condition have been published. Complications of toxic megacolon must be considered when the intestinal tract dilatation is greater than $6.0 \mathrm{~cm}$. We were concerned about the development of high-risk toxic megacolon in these 2 cases, which were successfully treated with tacrolimus and in which emergency surgery was avoided, and consider these cases to be highly informative and valuable.

Although case 2 was treated with tacrolimus and emergency colectomy could be avoided, extensive severe intestinal tract stenoses developed as the multiple deep ulcers healed. Benign colorectal stricture in UC is not at all rare. A study at Mount Sinai Hospital [7] found that 70 strictures were identified in 59 (5.1\%) of 1,156 patients. Seventeen $(24 \%)$ of these 70 strictures were malignant, and the remaining 53 (76\%) strictures were benign. Thus, 42 (3.6\%) of 1,156 patients had benign colorectal strictures. The following are thought to be mechanisms of benign stricture in UC. First, because of severe inflammation, inflammatory cells infiltrate not only the submucosal layer but also the muscle layer. Second, fibrosis of the submucosal layer and/or muscle layer occurs during the healing process. Lastly, ischemic or necrotic change occurs in the course of UC. There are case reports of patients with UC complicated by ischemic colitis and by aortitis syndrome.

In case 2, pathological examination showed no ischemic or necrotic changes or angiitis. Moderate inflammatory cells had infiltrated the submucosal and muscle layers, and this area had become severely fibrotic. This was regarded as the cause of the severe strictures. We thought that there is severe inflammation as the intestinal tract is expanded, and rapid mucosal healing had occurred due to the tacrolimus. 
Hayashi et al.: Two Cases of Severe Ulcerative Colitis with Colonic Dilatation Resolved with Tacrolimus Therapy

In conclusion, we believe tacrolimus to be a worthwhile method of treatment, with dosages determined in cooperation with the surgeons, in UC patients with intestinal tract dilatation such as that reported in these 2 cases. Tacrolimus should be considered as an option for the management of severe UC with colonic dilatation to prevent toxic megacolon or as a bridging therapy to surgery, thereby avoiding high-risk emergency colectomy. Further controlled studies with larger numbers of patients should be performed to confirm our findings and to establish a standard for management for incorporating tacrolimus in the treatment of toxic megacolon.

\section{Acknowledgement}

We thank Dr. Hisashi Hirata and Dr. Shoichi Tanaka (Department of Gastroenterology, Iwakuni Clinical Center) for providing images of endoscopy and barium enema examination of case 1 .

\section{References}

1 Danese S, Fiocchi C: Ulcerative colitis. N Engl J Med 2011;365:1713-1725.

2 Ogata H, Matsui T, Iida M, et al: A randomised dose finding study of oral tacrolimus (FK506) therapy in refractory ulcerative colitis. Gut 2006;55:1255-1262.

3 Ogata H, Kato J, Hirai F, et al: Double-blind, placebo-controlled trial oral tacrolimus (FK506) in the management of hospitalized patients with steroid-refractory ulcerative colitis. Inflamm Bowel Dis 2012;18:803-808.

4 Kino T, Hatanaka H, Miyata S, et al: FK-506, a novel immunosuppressant isolated from a Streptomyces. II. Immunosuppressive effect of FK-506 in vitro. J Antibiot (Tokyo) 1987;40:1256-1265.

5 Nakase H, Mikami S, Matsuura M, et al: Rescue therapy with tacrolimus for a patient with severe ulcerative colitis refractory to combination leukocytapheresis and high-dose corticosteroid therapy. Intern Med 2007;46:717-720.

6 Matsuhashi N, Nakajima A, Watanabe K, et al: Tacrolimus in corticosteroid-resistant ulcerative colitis. J Gastroenterol 2000;35:635-640.

7 Gumaste V, Sachar DB, Greenstein AJ: Benign and malignant colorectal strictures in ulcerative colitis. Gut 1992;33:938-941. 


\begin{tabular}{|c|c|c|}
\hline \multirow{3}{*}{$\begin{array}{r}\text { Case Reports in } \\
\text { Gastroenterology }\end{array}$} & \multirow{2}{*}{\multicolumn{2}{|c|}{ Case Rep Gastroenterol 2015;9:272-277 }} \\
\hline & & \\
\hline & DOI: $10.1159 / 000438784$ & $\begin{array}{l}\text { (c) } 2015 \text { S. Karger AG, Basel } \\
\text { www.karger.com/crg }\end{array}$ \\
\hline
\end{tabular}

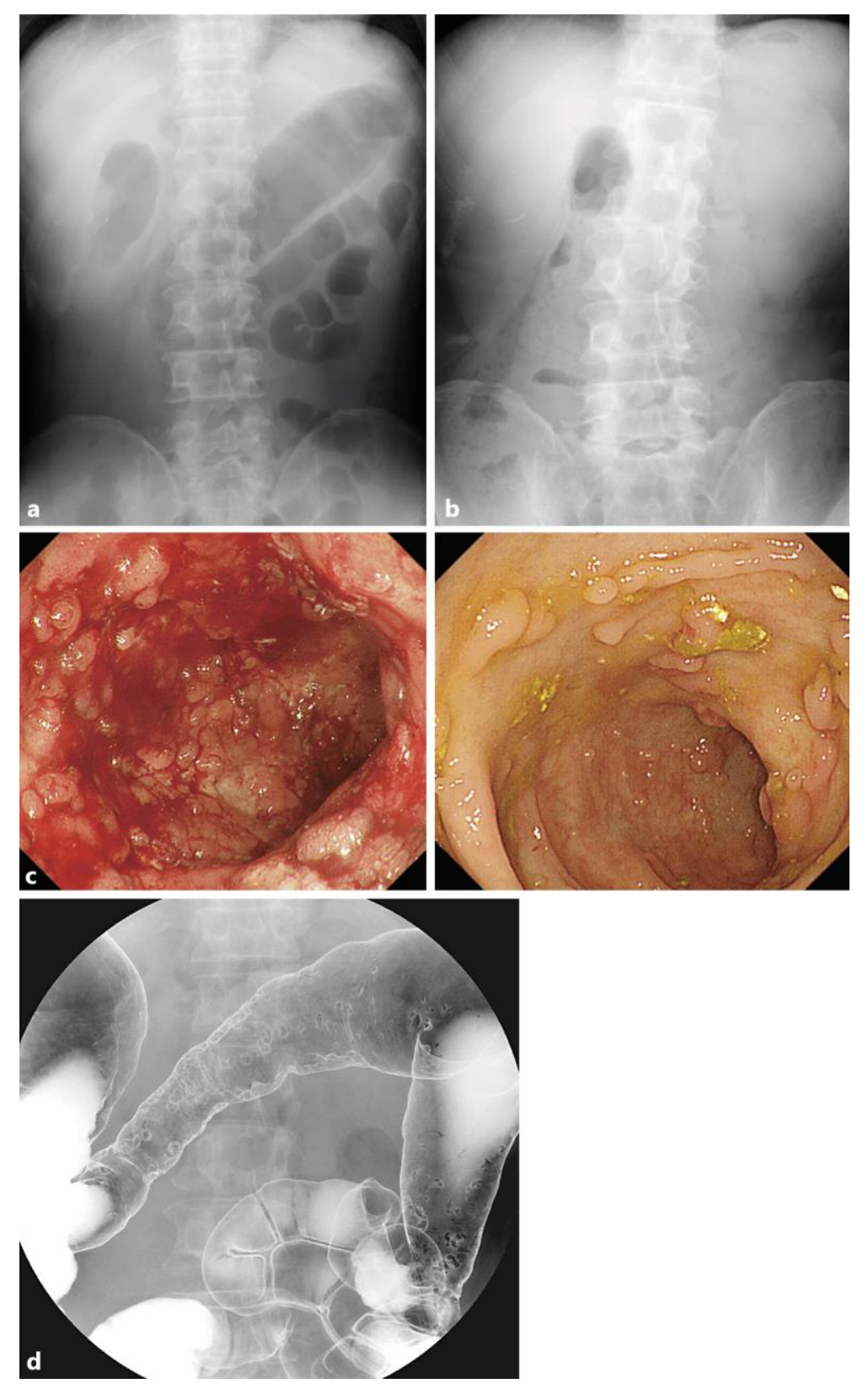

Fig. 1. a Abdominal X-ray performed before starting tacrolimus showed dilatation of the transverse colon. b After 2 weeks of therapy, colon dilatation disappeared. c Colonoscopy performed before starting tacrolimus showed edema, multiple ulcer, and spontaneous bleeding (left). Multiple ulcers had disappeared as a result of the treatment (right). $\mathbf{d}$ Barium enema examination showed pseudopolyposis. However, ulcer and stenosis were not detected. 


\begin{tabular}{ll|l} 
Case Reports in & \multicolumn{2}{l}{} \\
\cline { 2 - 3 } Gastroenterology & Case Rep Gastroenterol 2015;9:272-277 & $\begin{array}{l}\text { ○ 2015 S. Karger AG, Basel } \\
\text { www.karger.com/crg }\end{array}$ \\
\cline { 2 - 2 } & DOI: 10.1159/000438784 & $\begin{array}{l}\text { Hayashi et al.: Two Cases of Severe Ulcerative Colitis with Colonic Dilatation Resolved } \\
\text { with Tacrolimus Therapy }\end{array}$
\end{tabular}

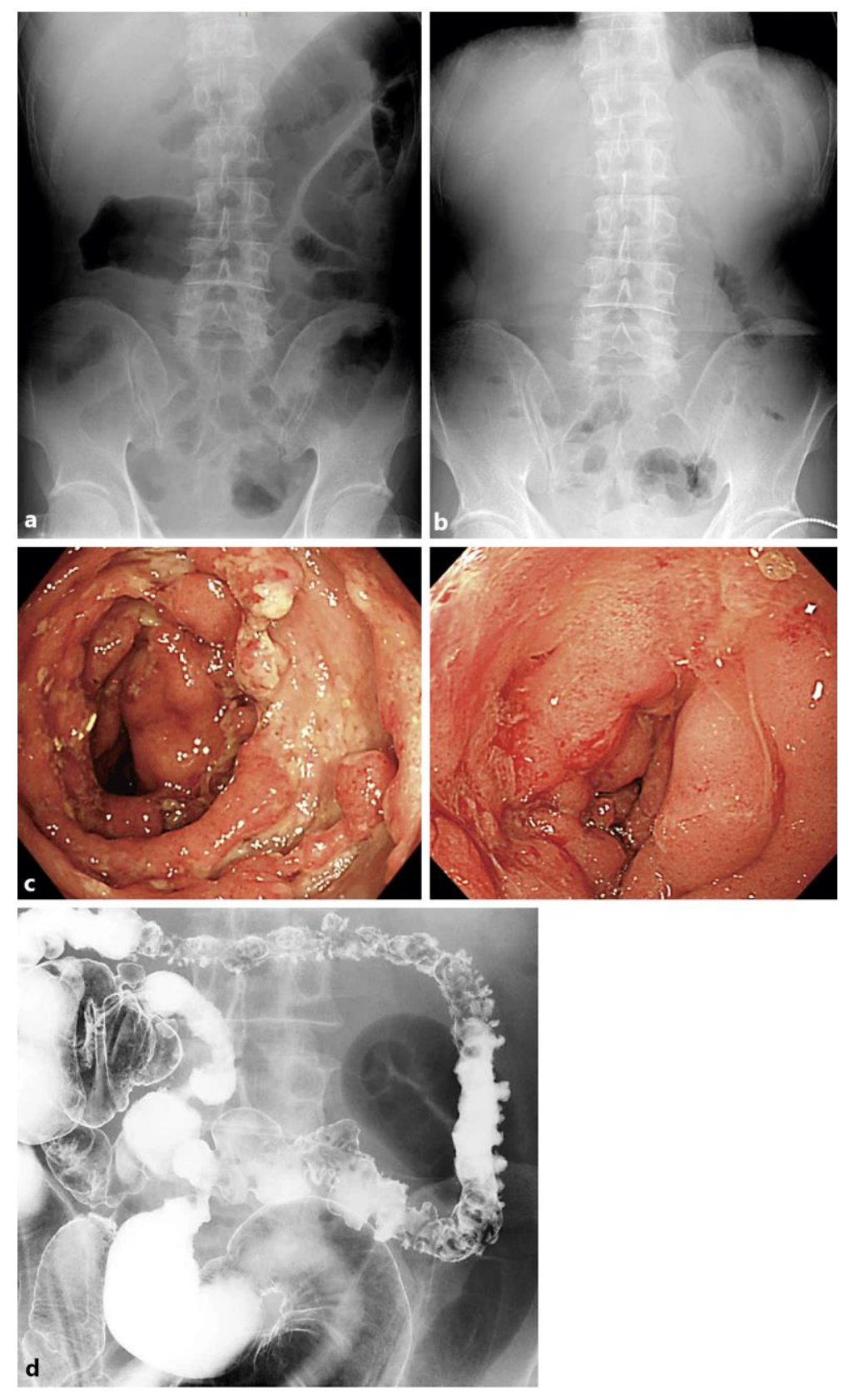

Fig. 2. a Abdominal X-ray performed before starting tacrolimus showed dilatation of the transverse colon. b After 2 weeks of therapy, colon dilatation disappeared as in case 1. c Colonoscopy performed before starting tacrolimus showed multiple deep ulcer (left). Ulcers still remained, and stenosis developed (right). d Barium enema examination showed multiple ulcers and extensive stenoses from the proximal sigmoid colon to the ascending colon. 